\title{
Divergencias en el tratamiento del cáncer de próstata localizado
}

\author{
González López R, Fernández Fernández E, Bueno Serrano G. \\ Servicio de Urología. Hospital Universitario Ramón y Cajal. Madrid.
}

Actas Urol Esp. 2008;32(10):955-956

$\mathrm{E}$ carcinoma de próstata es el segundo tumor maligno más frecuente entre los varones. Se estima que se diagnostican 680.000 nuevos casos al año en todo el mundo ${ }^{1}$ y que en España tiene una incidencia de unos 100 casos nuevos por 100.000 habitantes al año ${ }^{2}$. Su incidencia ha aumentado en los últimos años, por lo que en determinadas zonas es ya el tumor más frecuente en varones. En España, es la tercera causa de muerte por cáncer tras los tumores de pulmón y colorrectales, suponiendo un $10 \%$ de la mortalidad masculina por cáncer. Ante esta situación, los urólogos de todo el mundo han intentado diseñar unas pautas de actuación que permitan orientar el manejo de los pacientes diagnosticados de cáncer de próstata, para así poder ofrecerles el mejor tratamiento.

Así nacen las denominadas Guidelines, guías clínicas o protocolos en los que se intenta dar unas directrices que ayuden a la unificación de criterios y al consenso terapéutico. Sorprendentemente, al revisar la literatura al respecto, nos encontramos con que las dos grandes guías clínicas urológicas sobre el cáncer de próstata, la publicada por la Asociación Americana de Urología (AUA) ${ }^{3}$ y por la Asociación Europea (EAU) ${ }^{4}$, divergen en múltiples aspectos.

La Asociación Americana ha publicado recientemente unas guías clínicas en las que trata exclusivamente el cáncer de próstata localizado, sin valorar el tratamiento en los estadios siguientes, mientras que la EUA realiza una guía clínica de conjunto anual, en la que valora todas las situaciones clínicas del cáncer de próstata. Esta última indica claramente el límite de PSA a partir del cual realizar el screening de cáncer de próstata (incluso recomendando el descenso en el punto de corte a nivel general) y da recomendaciones diagnósticas; la AUA no analiza la metodología diagnóstica ni toma en cuenta valores de referencia o de corte del PSA. No hay que olvidar que el cáncer de próstata es una patología que el urólogo debe saber manejar no sólo en los estadios iniciales, sino en toda la evolución de la enfermedad, dado el gran abanico de posibilidades terapéuticas que existen a nuestro alcance y que pueden ser ofrecidas a los pacientes.

Otro de los puntos de mayor divergencia es la clasificación por estratificación del riesgo que ofrece la AUA, distinta a la que plantea la EUA. La Asociación Americana sitúa los carcinomas T2a en el grupo de los de bajo riesgo, mientras que la Europea los sitúa dentro de los tumores de riesgo moderado. Aun siendo los estadios Tla y Tlb los que más dudas terapéuticas pueden generar, la AUA no especifica su tratamiento, a diferencia de la AEU que valora su tratamiento y el de todos los estadios. En cambio, a la hora de plantear las diferentes opciones terapéuticas la Asociación Europea lo hace en base al estadiaje TNM y la Americana lo realiza en base a la estratificación del riesgo.

Otro de los aspectos que más polémica genera, como es la conservación bilateral o unilateral del paquete neurovascular en los tumores de bajo o moderado riesgo, figura como un punto específico en la guía clínica Europea, mientras que la Americana apenas sí comenta su manejo y no expone los criterios a seguir para realizarla.

Como guía clínica integral, la Asociación Europea aporta técnicas de seguimiento de cada opción terapéutica, tratamientos de segunda línea y de rescate, alternativas en cuidados paliativos y valoración de las técnicas mínimamente invasivas, así como sus resultados en estos momentos, junto con los criterios actuales para su aplicación. También especifica los actuales criterios para la aplicación de Braquiterapia y Crioterapia. La Asociación Americana no indica protocolos de seguimiento, ni terapias de rescate y tampoco valora técnicas minimamente invasivas para el tratamiento del cáncer de próstata. 
Tabla 1. Esquema de divergencias entre las guías clínicas de la Asociación Europea de Urología y la Asociación Americana

\section{ASOCIACIÓN EUROPEA}

- Guía clínica de Cáncer Próstata en conjunto.

- Indica límites PSA y da recomendaciones diagnósticas.

- Clasificación por estadiaje.

- Valora todos los estadios.

- Aporta seguimiento de cada opción terapéutica, tratamiento de segunda línea, paliativo...

- Especifica técnicas mínimamente invasivas (criterios y resultados).

- Criterios de Braquiterapia.

- Menor incidencia en preferencias del paciente.

- Indicación conservación NVS.

La Asociación Americana valora, por encima de otros criterios y siempre en situaciones de igualdad de resultados, la opinión del paciente para la toma de decisiones terapéuticas. La explicación exhaustiva por parte del profesional y la comprensión de las alternativas por parte del paciente se reflejan profundamente y resultan fundamentales para la toma consensuada de la decisión terapéutica en el carcinoma de próstata localizado de bajo y moderado riesgo. La Asociación Europea otorga un papel importante al paciente, pero sin depositar por completo la toma de la decisión final en manos de éste.

Ambas guías clínicas son un buen referente a la hora de plantearnos las opciones terapéuticas en los pacientes con cáncer de próstata localizado. Sin embargo, a nuestro juicio, el abordaje integral del tratamiento del cáncer de próstata en todas sus vertientes es mejor valorado y está expuesto con mayor claridad en las guías clínicas de la Asociación Europea de Urología. La práctica clínica diaria nos ha de hacer valorar las situacio- nes del día a día y las posibilidades de aplicación de estas directrices en nuestra labor cotidiana (Tabla 1).

\section{REFERENCIAS}

1. Vera Donoso CD. El tratamiento del cáncer de próstata: Presente y futuro, realidades y posibilidades. Actas Urol Esp 2007; 31(6): 575579.

2. Herranz F, Arrizabalaga M, Calahorra FJ, Carballido J, et al. El cáncer de próstata en la Comunidad de Madrid en el año 2000: Incidencia. Actas Urol Esp 2003; 27(5): 323-334.

3. Thompson I, Thrasher JB, Aus G, Burnett AL, Canby-Hagino ED, Cookson MS, D’Amico AV et al. Pcancer. Guideline for the management of clinically localized prostate cancer: 2007 Update. Grant for CDCP. American Urological Association Education and Research, Inc. 2007.

4. Heidenreich A, Aus G, Abbou CC, Bolla M, Joniau S, Matveev V et al. Guidelines on Prostate Cancer. European Association of Urology, Guidelines. 2007 Edition.

Correspondencia autor: Dra. R. González López Servicio de Urología. Hospital Universitario Ramón y Cajal Ctra. De Colmenar Viejo, km. 9,100 - 28034 Madrid Tel.: 913368000

E-mail autor: rakelgon@hotmail.com Información artículo: Editorial

Trabajo recibido: septiembre 2008 